\title{
Microcarrier Culture for Efficient Expansion and Osteogenic Differentiation of Human Fetal Mesenchymal Stem Cells
}

\author{
Tony Kwang-Poh Goh,, ${ }^{1, *}$ Zhi-Yong Zhang, ${ }^{2,3, *}$ Allen Kuan-Liang Chen,' Shaul Reuveny, \\ Mahesh Choolani, ${ }^{4}$ Jerry Kok Yen Chan, ${ }^{4-6}$ and Steve Kah-Weng Oh ${ }^{1}$
}

\begin{abstract}
Stirred microcarrier (MC) culture has been suggested as the method of choice for supplying large volumes of mesenchymal stem cells (MSCs) for bone tissue engineering. In this study, we show that in addition to the improvement in cell expansion capacity, MSCs propagated and harvested from MC culture also demonstrate higher osteogenic potency when differentiated in vivo or in vitro in three-dimensional (3D) scaffold cultures as compared with traditional monolayer (MNL) cultures. Cytodex 3 microcarrier-expanded human fetal MSC (hfMSC) cultures (MC-hfMSCs) achieved 12- to 16-fold expansion efficiency $\left(6 \times 10^{5}-8 \times 10^{5}\right.$ cells $\left./ \mathrm{mL}\right)$ compared to 4 - to 6fold $\left(1.2 \times 10^{5}-1.8 \times 10^{5}\right.$ cells $\left./ \mathrm{mL}\right)$ achieved by traditional MNL-expanded hfMSC culture (MNL-hfMSCs; $p<0.05)$. Both MC-hfMSCs and MNL-hfMSCs maintained similar colony-forming capacity, doubling times, and immunophenotype postexpansion. However, when differentiated under in vitro two-dimensional (2D) osteogenic conditions, MC-hfMSCs exhibited a 45-fold reduction in alkaline phosphatase level and a 37.5\% decrease in calcium deposition compared with MNL-hfMSCs $(p<0.05)$. Surprisingly, when MC-hfMSCs and MNLhfMSCs were seeded on 3D macroporous scaffold culture or subcutaneously implanted into nonobese diabetic/severe combined immunodeficient mice, MC-hfMSCs deposited 63.5\% $(p<0.05)$ more calcium and formed $47.2 \%(p<0.05)$ more bone volume, respectively. These results suggest that the mode of hfMSC growth in the expansion phase affects the osteogenic potential of hfMSCs differently in various differentiation platforms. In conclusion, MC cultures are advantageous over MNL cultures in bone tissue engineering because MC-hfMSCs have improved cell expansion capacity and exhibit higher osteogenic potential than MNL-hfMSCs when seeded in vitro into 3D scaffolds or implanted in vivo.
\end{abstract}

Key words: bioreactor; bone tissue engineering; fetal human mesenchymal stem cells; in vivo ectopic bone formation; microcarrier

\section{Introduction}

$\mathbf{M}$ ESENCHYMAL STEM CELLS (MSCs) are primitive cell types, which can be readily isolated from the bone marrow and other tissues and directed down to multiple mesenchymal lineages such as bone, cartilage, and fat. ${ }^{1,2}$ They can secrete multiple cytokines that aid tissue repair and are being investigated for a number of clinical indications due to their supportive functions ${ }^{3,4}$ with over a hundred clinical trials registered currently. ${ }^{2}$ Moreover, MSCs are nonimmunogenic $^{5,6}$ and largely not rejected in third party allogeneic transplantation paradigms, and they can be stored as offthe-shelf cell sources. ${ }^{2}$

Since the default pathway for MSCs is the osteogenic lineage, ${ }^{7,8}$ they have been investigated as promising cell sources for bone tissue engineering (BTE). We have shown previously

\footnotetext{
${ }^{1}$ Bioprocessing Technology Institute, Agency for Science, Technology, and Research (A*STAR), Singapore.

${ }^{2}$ Department of Plastic and Reconstructive Surgery, Shanghai 9th People's Hospital, School of Medicine, Shanghai Jiao Tong University, Shanghai, China.

${ }^{3}$ National Tissue Engineering Center, Shanghai, China.

${ }^{4}$ Experimental Fetal Medicine Group, Department of Obstetrics and Gynecology, Yong Loo Lin School of Medicine, National University of Singapore, Singapore.

${ }^{5}$ Cancer and Stem Cell Biology Program, Duke-NUS Graduate Medical School, Singapore.

${ }^{6}$ Department of Reproductive Medicine, KK Women's and Children's Hospital, Singapore.

*These authors contribute equally to this article.
} 
that hfMSCs have superior expansion and osteogenic differentiation potential compared to perinatally derived MSCs from umbilical cord, adult adiposal, and bone marrow tissues. ${ }^{8}$ When seeded onto macroporous poly- $\varepsilon$-caprolactonetri-calcium-phosphate (PCL-TCP) scaffolds and dynamically cultured, these hfMSC-grafts can rescue critical-sized defects through enhanced neovascularization. ${ }^{9}$

The clinical use of MSCs for BTE requires a large number of culture-expanded MSCs. For example, in a phase II clinical trial of nonunion fracture conducted by University of Liege, Belgium (ClinicalTrials.gov Identifier: NCT01429012), a dose of $40 \times 10^{6}$ cells per patient has been proposed, and it was previously reported by Mesoblast Limited that fracture healing rates are closely linked to the transplanted dose of MSCs. ${ }^{10}$ Since the yield of MSCs in culture is low $\left(2 \times 10^{4}-\right.$ $3 \times 10^{4}$ cell $/ \mathrm{cm}^{2}$ ), achieving these cell quantities in conventional monolayer (MNL) culture is problematic. ${ }^{11}$ A culture surface area of $0.13-0.20 \mathrm{~m}^{2}$ will be needed for supplying cells for one treatment. Furthermore, this MNL operation, which requires use of multiple flasks is labor intensive, requiring multiple rounds of subculturing; is susceptible to contamination; and lacks control and monitoring of culture conditions. $^{12,13}$

In order to overcome the inefficiencies of MNL cultures, microcarrier (MC)-based cultures, in which cells are propagated on the surface of small beads suspended in growth medium by slow agitation, has been proposed. This enables a scalable homogenous culture with high surface area to volume ratio to be achieved. One liter culture containing $5 \mathrm{mg} / \mathrm{mL}$ MCs (Cytodex 3, GE Healthcare) can provide $1.35 \mathrm{~m}^{2}$ for cell growth. ${ }^{14}$

Different groups have investigated the expansion of a variety of human MSCs in MC culture and their use for studying bone tissue differentiation and engineering. The majority of these MC-related publications have reported that the cells grown on $\mathrm{MC}$ retained their multilineage differentiation potential as demonstrated by alkaline phosphatase (ALP) activity, von Kossa, Oil red O, and/or Alcian blue staining. ${ }^{15-18}$ Some publications reported on the up-regulation of osteogenesisrelated genes such as collagen type 1, bone sialoprotein, ALP, osteocalcin, and osteopontin by quantitative real-time polymerase chain reaction (qRT-PCR) and/or ALP activity during the early differentiation phase over 2-4 weeks. ${ }^{18-21}$ Only Yang and co-workers have brought their work further by transplanting their Cultispher ${ }^{\circledR} \mathrm{S}$ MC expanded rat MSCs directly into rat's nonunion femoral defects providing a proof-of-concept of the utility of MC expanded MSCs for BTE. $^{22,23}$ Still, there is a lack of data comparing MC and MNL expanded human fetal MSCs in a head-to-head and comprehensive manner of their subsequent long-term ( 3 months) osteogenic potency in in vitro two-dimensional (2D), threedimensional (3D), and in vivo differentiation conditions, which is most relevant to clinical applications of bone repair.

In this work, hfMSCs expanded on static MNL (MNLhfMSC) and agitated Cytodex $3 \mathrm{MC}$ (MC-hfMSC) cultures were evaluated for their immunophenotype, colony-forming capacity, and osteogenic differentiation efficacy on in vitro $2 \mathrm{D}$ MNL culture and $3 \mathrm{D}$ scaffold culture and in in vivo subcutaneous transplanted nonobese diabetic/severe combined immunodeficient (NOD/SCID) mice. We have found that beyond the large-scale expansion potential of hfMSCs propagated in stirred MC culture the different mode of cell propagation in the MC culture resulted in higher osteogenic efficiency in 3D conditions in both in vitro scaffold and in vivo differentiation assays. These findings suggest that the MC-hfMSC expansion platform is advantageous over traditional static MNL culture in terms of expansion capability, simplicity, and the preservation of high osteogenic potency in 3D scaffold culture and in vivo ectopic bone formation.

\section{Materials and Methods}

\section{Ethics of obtaining and culturing hfMSCs \\ and responsible use and care of laboratory animals}

Fetal tissue collection was approved by the Domain Specific Review Board of National University Hospital, Singapore (DSRB-D-06-154) in compliance with international guidelines regarding the use of fetal tissue for research. ${ }^{24}$ Pregnant women gave separate written consent for the clinical procedure and for the use of fetal tissue for research purposes. Fetal tissues were collected after clinically indicated termination of pregnancy, and gestational age was determined by crown-rump length measurements. In these experiments, a 13-week gestation sample was used.

hfMSCs were isolated from bone marrow through plastic adherence and culture expansion and characterized through immunophenotyping, colony-forming capacity, and tri-lineage differentiation into osteoblasts, adipocytes, and chondrocytes as previously described. ${ }^{8,25}$ Briefly singlecell suspensions of fetal bone marrow were prepared by flushing the marrow cells out of humeri and femurs using a 22-gauge needle into Dulbecco's modified Eagle's medium (DMEM, Sigma-Aldrich)-GlutaMAX (Gibco) supplemented with $10 \%$ fetal bovine serum (FBS), $50 \mathrm{U} / \mathrm{mL}$ penicillin, and $50 \mathrm{mg} / \mathrm{mL}$ streptomycin (Gibco), referred herein as $\mathrm{D} 10$, and then plated onto $100-\mathrm{mm}$ dishes at $10^{6}$ mononuclear cells/mL of D10 medium, $10 \mathrm{~mL}$ per dish. Media were changed every 2-3 days, and nonadherent cells were removed and subcultured at $5 \times 10^{3} \mathrm{cell} / \mathrm{cm}^{2}$ to subconfluence. hfMSCs at passage 7 were used for both characterization and the experiments described here. All cultures were maintained at $37^{\circ} \mathrm{C}, 5 \% \mathrm{CO}_{2}$ humidified incubator.

NOD-SCID mice (approximately 8 weeks old, $n=5$ ) were acquired through NUS Laboratory Animals Centre and all procedures were approved by the Institutional Animal Care and Use Committee (IACUC) at National University of Singapore.

\section{Preparation of MCs}

MCs used in this study (Table 1) were prepared according to manufacturers' instructions. Briefly, MCs were washed with phosphate-buffered saline (PBS; $\mathrm{Mg}^{2+}, \mathrm{Ca}^{2+}$ free) three times; thereafter they were sterilized by autoclaving at $121^{\circ} \mathrm{C}$ for $20 \mathrm{~min}$. Before use, MCs were rinsed three times with D10 medium. For MC work, only plastic or siliconized $\left(\right.$ Sigmacote ${ }^{\circledR}$, Sigma-Aldrich) glass equipment were used in order to prevent MC adsorption.

\section{Cultivation of hfMSCs on MC in spinner flask}

One-hundred-milliliter spinner flasks (Scientific Industries; Bell-Flo ${ }^{\mathrm{TM}}$ ) containing MCs suspended in $50 \mathrm{~mL}$ of D10 medium were seeded with $5 \times 10^{6}$ cells (Table 1) at 3 cells/ 
Table 1. Characteristics of Microcarriers Used in this Study

\begin{tabular}{|c|c|c|c|c|c|c|c|}
\hline Microcarrier & Shape & $\begin{array}{c}\text { Dimension } \\
(\mu \mathrm{m})\end{array}$ & $\begin{array}{c}\text { Surface } \\
\text { area }\left(\mathrm{cm}^{2} / \mathrm{mg}\right. \\
\text { dry weight })\end{array}$ & Material & Surface properties & $\begin{array}{c}\text { Working } \\
\text { concentration } \\
(m g / m L)\end{array}$ & Manufacturer \\
\hline Cytodex 1 & Spherical & $180 \pm 45$ & 4.40 & $\begin{array}{l}\text { Cross-linked } \\
\text { dextran }\end{array}$ & $\begin{array}{l}\text { Positive charge: } \\
\text { N,N-diethylaminoethyl } \\
\text { (DEAE). Charge density } \\
\text { of } 1.4-1.6 \text { meq/g } \\
\text { dry weight. }\end{array}$ & 2.45 & GE Healthcare \\
\hline Cytodex 3 & Spherical & $175 \pm 40$ & 2.70 & $\begin{array}{l}\text { Cross-linked } \\
\text { dextran }\end{array}$ & $\begin{array}{l}\text { Denatured type } 1 \text { collagen } \\
\left(16 \mathrm{mg} / \mathrm{cm}^{2}\right)\end{array}$ & 4.17 & GE Healthcare \\
\hline Cultispher GL & Spherical & $230 \pm 90$ & Not available & $\begin{array}{l}\text { Cross-linked } \\
\text { gelatine }\end{array}$ & $\begin{array}{l}\text { Macroporous, gelatin } \\
\quad(50-\text { to } 70-\mu \mathrm{m} \text { pore size })\end{array}$ & 12.03 & Sigma-Aldrich \\
\hline $\begin{array}{l}\text { HyQsphere } \\
\text { P102-L }\end{array}$ & Spherical & $120 \pm 30$ & 0.48 & $\begin{array}{l}\text { Cross-linked } \\
\text { polystyrene }\end{array}$ & Cross-linked polystyrene & 2.79 & Hyclone \\
\hline
\end{tabular}

bead ratio. The culture was agitated in a spinner flask impeller (Bellco Glass Inc., cat. no. 1965-10100) for $24 \mathrm{~h}$ at $25 \mathrm{rpm}$, thereafter $50 \mathrm{~mL}$ of D10 medium was added and agitation rate was increased to $30 \mathrm{rpm}$. The culture was maintained for up to 12 days, and $50 \%$ of the culture medium was replenished with fresh D10 medium every other day.

\section{Upscaling of MC-hfMSC culture}

A 1-L bioreactor (Sartorius Biostat ${ }^{\circledR}$ B-DCU) containing $8.34 \mathrm{mg} / \mathrm{mL}$ MCs suspended in $500 \mathrm{~mL}$ of D10 medium was seeded with $5 \times 10^{7}$ cells. The culture was agitated for $24 \mathrm{~h}$ at $30 \mathrm{rpm}$; thereafter $500 \mathrm{~mL}$ D10 medium was added and agitation rate was increased to $50 \mathrm{rpm}$. The culture was maintained for up to 8 days, and $50 \%$ of the culture medium was replenished with fresh D10 medium every other day. Overhead aeration was carried out using a mass flow controller to regulate the mixture of gases entering the bioreactor. The minimum dissolved oxygen concentration was set at $30 \%$ of atmospheric and $\mathrm{pH}$ was controlled by $\mathrm{NaOH}$ and $\mathrm{CO}_{2}$ gas.

Concentrations of metabolites such as glucose, glutamine, lactate, and ammonia were measured using Bioprofile 100 plus (NOVA). Specific consumption and production rate of metabolites $\left(\mathrm{q}_{\mathrm{m}}\right)$ and yield ratios $\left(\mathrm{Y}_{a / b}\right)$ were calculated as previously described. ${ }^{26}$

\section{Harvesting of hfMSCs from MCs}

After 9 days of propagation, $20 \mathrm{~mL}$ of MC cultures were transferred to a $50-\mathrm{mL}$ tube and washed three times with $8.3 \mathrm{~mL}$ of PBS $\left(\mathrm{Mg}^{2+}, \mathrm{Ca}^{2+}\right.$ free) by decantation. Harvesting was carried out using either $4.2 \mathrm{~mL}$ of $0.25 \%$ Trypsin-EDTA (Gibco), $20 \mathrm{mg} / \mathrm{mL}$ collagenase type I (Sigma-Aldrich), or TrypLE ${ }^{\mathrm{TM}}$ Express $(1 \times)(\mathrm{Gibco})$, at $37^{\circ} \mathrm{C}$ with agitation by reciprocal mixing at $90^{\circ} \mathrm{C}, 90$ oscillations per minute (Grant-Bio rotator-mixer; cat. no. PTR-35). After 5-15 min of digestion, $4.2 \mathrm{~mL}$ of fresh D10 medium was added to stop the enzymatic reactions, and the cells were separated from the MCs by sieving through $70-\mu \mathrm{m}$ cell strainers (BD Falcon). Cell counts were taken every $5 \mathrm{~min}$.

\section{Measurement of MC culture aggregations}

$\mathrm{MC}$ aggregation rates were measured by phase contrast inverted light microscopy. Using $100 \times$ magnifications, five random fields were scanned, counted, and measured for the number of aggregates and aggregate size. Aggregates were defined as clumps with more than two MCs linked by cell bridges.

\section{In vitro 2D osteogenic differentiation of harvested hfMSCs}

Osteogenic induction was done by plating $2 \times 10^{4} \mathrm{cells} / \mathrm{cm}^{2}$ immediately after harvesting from Nunc six-well tissue culture plate $\left(9.6 \mathrm{~cm}^{2} /\right.$ well, Cat. no. 140675$)$ or MCs onto tissue culture dish containing osteogenic differentiation medium (D10 supplemented with $10 \mathrm{mM} \beta$-glycerophosphate, $10 \mathrm{nM}$ dexamethasone, and $0.2 \mathrm{mM}$ ascorbic acid). The cultures were incubated for 21 days with osteogenic differentiation medium, and media exchange was done every other day.

\section{In vitro $2 D$ osteogenic differentiation of MC-hfMSC-unharvested culture}

Homogenous samples were taken from MC spinner culture (after 9 days of propagation), and cell densities were determined by nuclei count (as described in the Cell counting section). An adequate volume of MC spinner culture that contained the cell numbers required for differentiation was transferred to a 50-mL tube. The culture was left standing for $5 \mathrm{~min}$ to allow unharvested MC-hfMSCs to settle. The supernatant was removed and osteogenic differentiation medium was added to adjust the cell density to $1 \times 10^{5}$ cells $/ \mathrm{mL}$. Then, $2 \mathrm{~mL}$ of culture was plated onto each well of a six-well tissue culture plate. The culture was incubated for 21 days with osteogenic differentiation medium and medium exchange was done every other day.

\section{In vitro $3 D$ (scaffold) osteogenic differentiation of hfMSCs}

Cells were suspended at high cell density of $2 \times 10^{7}$ cells / $\mathrm{mL}$. Using a micropipette, $1 \times 10^{6}$ cells $(50 \mu \mathrm{L})$ were loaded on $4 \mathrm{~mm} \times 4 \mathrm{~mm} \times 4 \mathrm{~mm}$ macroporous $(70 \%$ free volume, $2.2 \times 10^{4}$ cells $/ \mathrm{mm}^{3}$ of free volume) PCL-TCP (Osteopore International) that were placed individually in each well of a 12 -well plate. The plates were incubated at $37^{\circ} \mathrm{C}$ in $5 \%$ $\mathrm{CO}_{2}$, humidified incubator for $3 \mathrm{~h}$ to allow attachment of cell to the scaffolds. Thereafter, $2 \mathrm{~mL}$ of osteogenic differentiation medium was added slowly into the well to cover the scaffolds. The cultures were maintained for 28 days, with osteogenic differentiation medium exchange done every other day. 


\section{In vivo transplantation of hfMSCs and ectopic bone formation}

Three groups of implants were generated in 1.5-mL eppendorf tubes to form a round pellet. In the cellular implant groups, $1 \times 10^{6} \mathrm{hfMSC}$ were harvested from either MC or MNL cultures and centrifuged at $400 \mathrm{~g}$ at $4^{\circ} \mathrm{C}$ for $5 \mathrm{~min}$. The resulting pellets were mixed with $100 \mu \mathrm{L}$ of fibrin glue (Tisseel Kit, Baxter) and $50 \mathrm{mg}$ of hydroxyapatite (HA) powder (kindly provided by Prof. Eng-San Thian from the Department of Mechanical Engineering, National University of Singapore). In the third group, only fibrin glue and HA powder were used to generate acellular implants. All implants were incubated for $30 \mathrm{~min}$ at room temperature after addition of the fibrin glue and HA powder, followed by incubation in osteogenic differentiation medium for $1 \mathrm{~h}$ at $37^{\circ} \mathrm{C}$ in a $5 \% \mathrm{CO}_{2}$ humidified incubator before implantation.

A 10-mm longitudinal dorsal skin incision was created on anesthetized NOD/SCID mice (Charles Rivers, Australia). Subcutaneous pouches were produced by using a sterile blunt end forceps through blunt dissections. Each mouse received three implants (one implant from each of the above groups), two on opposite sides of the upper midline dorsa area and one at the lower dorsa area. The wounds were closed with interrupted 6-O vicryl sutures and retrieved for analysis by micro-computed tomography (micro-CT) 3 months post transplantation. For each implant group, five implants were generated and transplanted as previously described. ${ }^{8}$

\section{Cell counting}

Total cell count of attached cells on MC and MNL was measured by nuclei count (Nucleocounter NC-100, ChemoMetec) according to the manufacturer's instructions. Nonattaching cells were counted by the trypan blue exclusion method.

\section{Immunophenotypic analysis of hfMSCs}

Viable hfMSCs harvested from MNL or MC cultures were analyzed for CD34, CD73, CD90, CD105, and STRO-1 (Biolegend) surface markers through flow cytometer (BD FACS Calibur) as previously described. ${ }^{8}$

\section{Colony-forming unit-fibroblast assay}

Colony-forming unit-fibroblast (CFU-F) assays were performed by seeding 100 cells onto $100-\mathrm{mm}$ tissue culture dish $\left(2\right.$ cells $/ \mathrm{cm}^{2}$ ) containing $10 \mathrm{~mL}$ of D10. After 14 days of incubation, colonies were visualized by crystal violet staining as described previously; colonies having a diameter of $2 \mathrm{~mm}$ or more were counted. ${ }^{8}$

\section{ALP assay}

The ALP concentration in cell lysates was measured using SensoLyte pNPP Alkaline Phosphatase Assay Kit (AnaSpec) following the manufacturer's instructions. Results were normalized to total cell count obtained using nuclei count (Nucleocounter, ChemoMetec).

\section{Calcium deposition assay}

Differentiated 2D cultures were washed three times with PBS $\left(\mathrm{Mg}^{2+}, \mathrm{Ca}^{2+}\right.$ free), and the extracellular calcium deposit was dissolved with 0.5 normality $(\mathrm{N})$ acetic acid for $15 \mathrm{~min}$ at room temperature. Similarly 3D scaffolds were washed three times with PBS $\left(\mathrm{Mg}^{2+}, \mathrm{Ca}^{2+}\right.$ free) and incubated with $0.5 \mathrm{~mL}$ of $0.5 \mathrm{~N}$ acetic acid per scaffold for $60 \mathrm{~min}$ at room temperature with occasional agitation. Eluted calcium was quantified using calcium assay kit (BioAssay System) according to the manufacturer's instructions. Calcium depositions of nondifferentiated hfMSCs cultured in DMEM with serum (i.e., MSC culture media) were measured and used as negative control. Results were either normalized to total cell count or total double-stranded (ds)DNA content measured by nuclei count (Nucleocounter, ChemoMetec) or PicoGreen dsDNA quantification assay (Molecular Probes), according to manufacturer's instructions.

\section{PicoGreen dsDNA quantification assay of the scaffold cultures}

Each scaffold was subjected to three cycles of repeat freeze thawing, and followed by incubation with $0.5 \mathrm{~mL}$ of trypsin and collagenase mixture (1:1 ratio) for $1 \mathrm{~h}$ at $37^{\circ} \mathrm{C}$ with occasional agitation. Cell lysates were harvested by centrifuging the scaffold at $14,000 \mathrm{~g}$ for $5 \mathrm{~min}$. Double-stranded DNA content in the samples was quantified by PicoGreen dsDNA Quantification kit (Molecular Probes) according to manufacturer's instructions.

\section{Micro-CT of ectopic bone tissue}

After 3 months of transplantation, implants $(n=5$ from each group) were harvested, fixed with $2.5 \%$ glutaraldehyde, and imaged using Micro-CT, 1076 SkyScan machine (SkyScan) as previously described. ${ }^{8}$ Acellular implants (serving as negative controls) that had been implanted over the same period of time were imaged and used as a baseline.

\section{Histology}

Ectopic bone samples were harvested 3 months after transplantation. Samples were fixed, embedded, sectioned, and stained as previously described. ${ }^{9}$ Briefly, hematoxylin and eosin, von Kossa, and Masson's trichrome stains were used to detect general tissue morphology, calcium deposits, and woven and mature bone structure revealing the presence of collagen I, respectively.

\section{Statistical analysis}

Data are shown as mean \pm standard deviation. One-way analysis of variance (ANOVA) was carried out to determine the significance between independent experimental groups. Once ANOVA analysis shows that there are significant differences between independent experimental groups, post hoc Tukey tests were carried out to determine which experimental groups were significantly different from the rest using GraphPad Prism version 4.03 for Windows (GraphPad Software); $p$ values $<0.05$ were considered as significant.

\section{Results}

Establishment of an efficient MC-hfMSC cell expansion system

To explore scale-up potential, four commercially available MCs (Cytodex1, Cytodex3, Cultispher GL, and HyQspheres; 
Table 1) were tested for their ability to support hfMSC growth under stirring conditions in $100 \mathrm{~mL}$ spinner flasks. These MCs are made up of different matrices (cross-linked dextran, polystyrene, and gelatin), surface properties (positively charged, tissue culture-treated polystyrene, collagen coated, and gelatin), porosity (microporous , macroporous), and sizes (120-230 $\mu \mathrm{m}$; Table 1). ${ }^{16,17,27}$ Since over-confluency of MSC culture is known to cause adverse effects on its osteogenic differentiation potential $^{28,29}$ we chose a low inoculum ratio of three cells per bead for this study. High seeding ratio of above five cells per bead can generate over-confluency on the smaller diameter MCs. ${ }^{20,30}$

Thus, spinner flasks were seeded at cell densities of $5 \times 10^{4}$ cells/mL with Cytodex 1, Cytodex 3, Cultispher GL, and HyQsphere P102-L MC at a ratio of three cells per bead. Low agitation speed ( $25 \mathrm{rpm}$; spinner flask impeller, Bellco Glass Inc., cat. no. 1965-10100) for the first $24 \mathrm{~h}$ was used in order to allow efficient cellular distribution and attachment. Thereafter, it was increased to $30 \mathrm{rpm}$ to prevent aggregation and ensure optimal gaseous exchange to the culture. The cell growth kinetics for all MC cultures exhibited a lag phase of 4 days before an exponential phase was reached (Fig. 1). Slow growth (doubling time $61 \pm 5 \mathrm{~h}$ ) and low final cell yields of $3.8 \times 10^{5} \pm 0.1 \times 10^{5}$ cells $/ \mathrm{mL}$ (7.6-fold expansion) were obtained in the Cultispher GL MC culture. These low yields can be attributed to difficulties in achieving efficient cell spreading on the Cultispher GL-MC surface, which is not smooth due to its macroporous nature (50- to $70-\mu \mathrm{m}$ pore size), ${ }^{31}$ and/or as a result of limitation of nutrient supply due to the formation of comparatively large aggregates $(576 \pm 133 \mu \mathrm{m}$, Fig. 2.) generated in these cultures $(83 \pm 5 \%$ aggregation on day 8). In HyQSpheres P-102-L cultures, we observed significant cell loss during the initial 4 days of cul- ture, which was due to the low efficiency of cell attachment to these noncharged tissue culture treated polystyrene MC (56 $\pm 4 \%$ cell attachment efficiency achieved as compared with $90 \pm 5 \%$ in Cytodex 1 and 3). Thereafter, HyQSpheres P-102-L MCs supported active cellular expansion, with a doubling time of $33 \pm 2 \mathrm{~h}$, achieving final cell densities of $6.8 \pm 0.1 \times 10^{5}$ cells $/ \mathrm{mL}$ on day 11 (13.6-fold expansion) (Fig. 1). However, significant hfMSC-MC aggregates were formed in $88 \pm 6 \%$ of MCs by day 12 of culture, which was a result of cell-bridges forming between the MCs (Fig. 2).

We obtained similar growth kinetics of hfMSCs seeded onto positively charged Cytodex 1 and collagen-coated Cyto$\operatorname{dex} 3$, which are both dextran based MCs (Fig. 1). hfMSCs attached and spread on the surface of these two MCs within a few hours after seeding. At $24 \mathrm{~h}, 90 \pm 5 \%$ of the seeded hfMSCs were found to be attached and spread onto the MC surfaces (Fig. 2). The exponential phase of cellular expansion occurred after a lag phase, achieving similar maximal cells yields of $6.5 \pm 0.1 \times 10^{5}$ and $6.8 \pm 0.2 \times 10^{5}$ cells $/ \mathrm{mL}$ (13- to 13.6 -fold expansion) for Cytodex 1 and $3 \mathrm{MCs}$, respectively, on day 11 . As the cells became confluent, hfMSC-MC aggregation was observed, with lower levels seen in Cytodex 3 compared with Cytodex 1 by day 12 (10 $4 \%$ versus $24 \pm 5 \%)$. Cell viability of more than $95 \%$ (trypan blue exclusion method) was measured in both cultures after harvesting by trypsin. In comparison, MNL cultures became confluent over 4 to 5 days.

In this head-to-head comparison of the different MCs for expansion of hfMSCs, Cytodex 3 MCs were able to generate the largest fold expansion while maintaining the lowest aggregation rates compared with the other three MCs. Since aggregation can lead to inactivation of osteogenic programming, and may result in a reduction in osteogenic

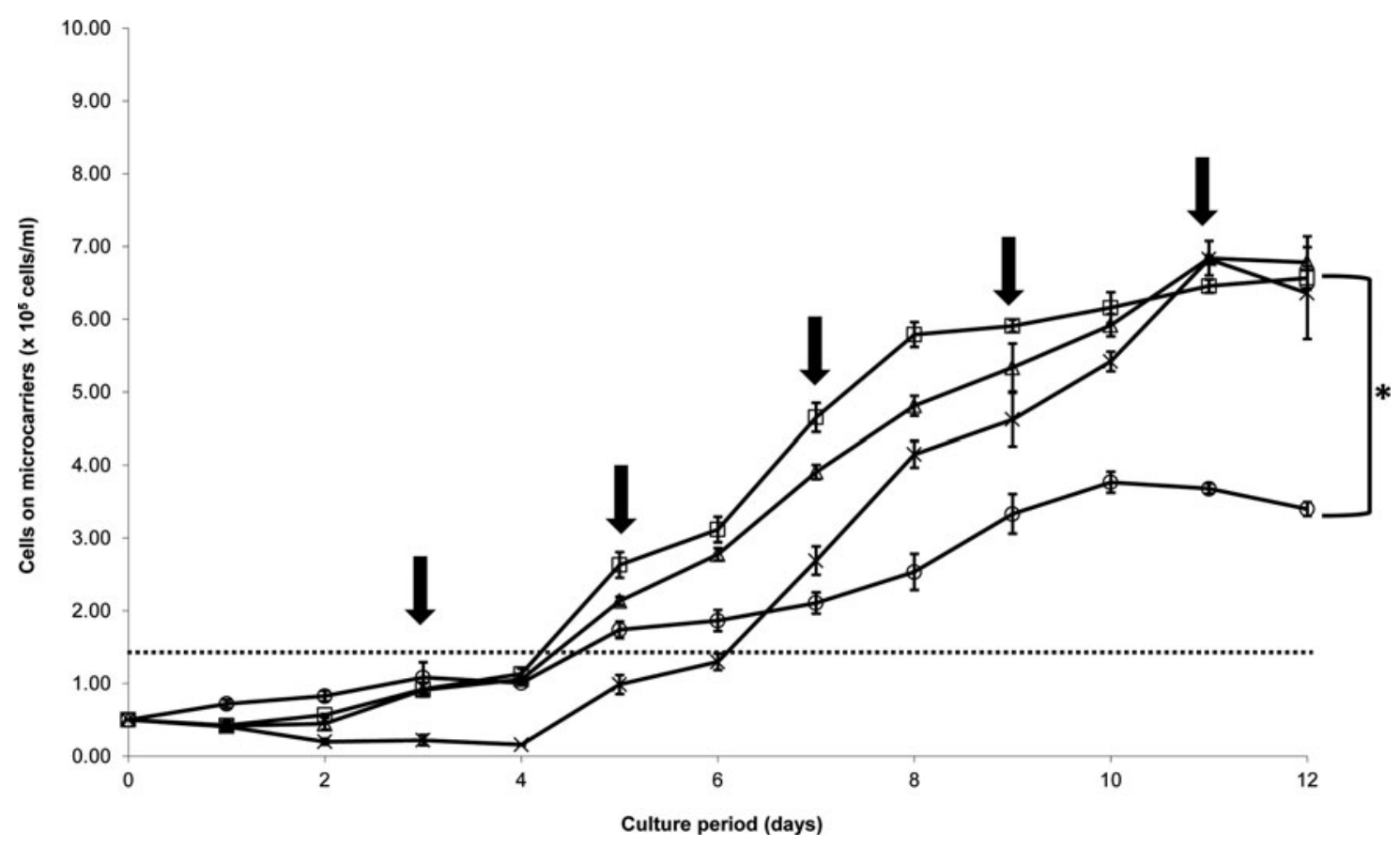

FIG. 1. Growth kinetics of human fetal mesenchymal stem cells (hfMSCs) on different microcarriers in stirred spinner flasks on different microcarriers: $(\square)$ Cytodex 1, $(\triangle)$ Cytodex 3, $(\bigcirc)$ Cultispher GL, $(\times)$ HyQSpheres P102-L. Cultures maintained for 12 days, with half change of fresh D10 medium every other day (indicated by $\downarrow$ ). Statistical analysis indicate that Cultispher GL had achieved significantly lower final cell density among the four microcarriers $\left({ }^{*} p<0.01\right)$. The dashed line indicates maximal cell yield in monolayer cultures. 


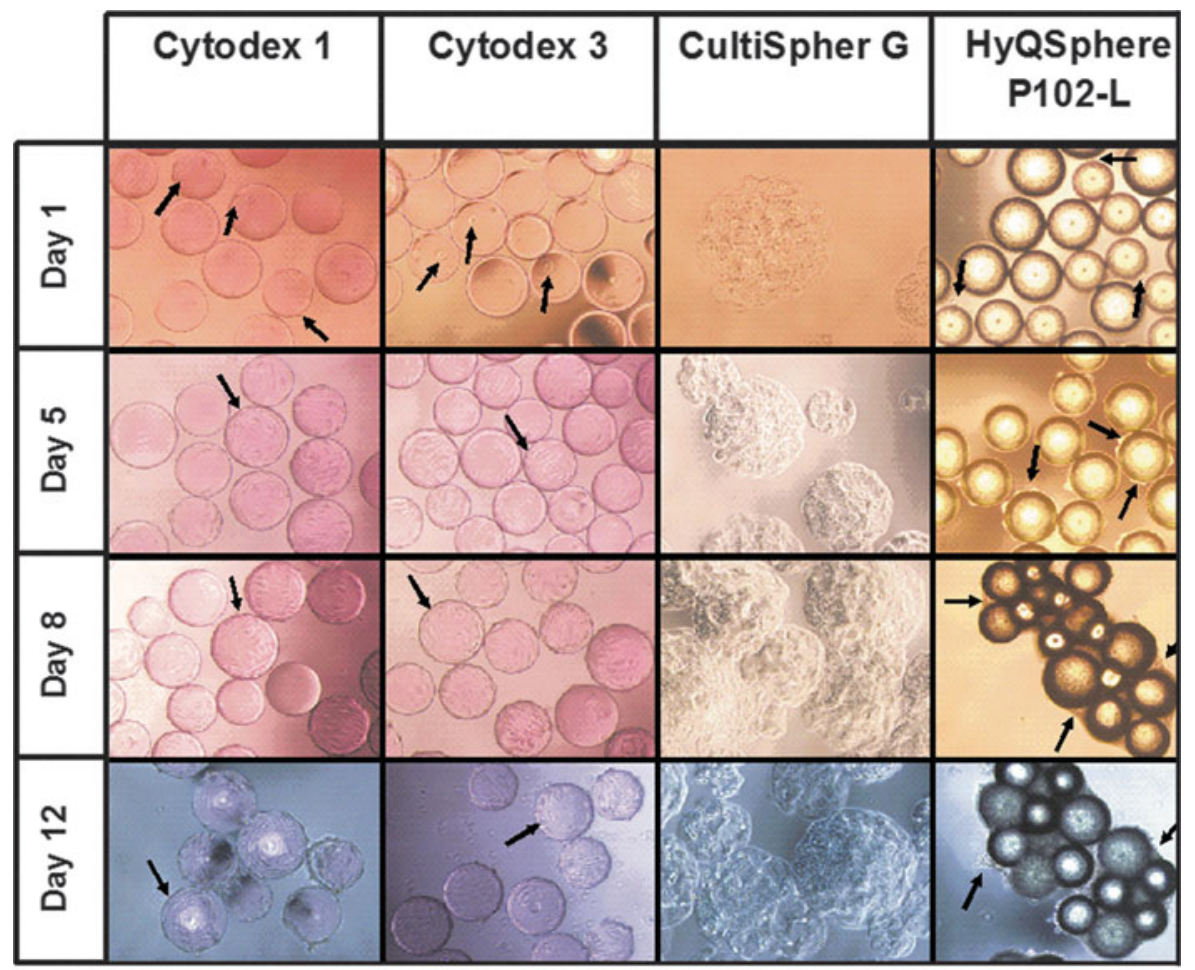

$10 \overline{0} \mu \mathrm{m}$
FIG. 2. Morphology of hfMSCs cultured on various microcarriers from days 1 to 12 . potential, ${ }^{28,29}$ Cytodex 3 MCs were chosen for further studies. Reproducibility of hfMSC Cytodex $3 \mathrm{MC}$ cultures in spinner flasks was demonstrated by execution of eight separate runs with an average maximal cell yield of $8.3 \times 10^{5} \pm$ $0.9 \times 10^{5}$ cells $/ \mathrm{mL}(17- \pm 2$-fold expansion) and a doubling time of $48 \pm 5 \mathrm{~h}$, as compared with cell yield of $1.5 \times 10^{5} \pm 0.3 \times 10^{5}$ cells $/ \mathrm{mL}$ ( $5 \pm 1$ fold expansion) and doubling time of $36 \pm 4 \mathrm{~h}(p<0.05)$ in MNL culture. The phenom- enon of longer doubling time observed in MC culture might be due to shear stress as reported in earlier literature. ${ }^{19,23,32}$

All hfMSCs harvested from both MNL and Cytodex $3 \mathrm{MC}$ cultures maintained their immunophenotype of CD73, CD90, and CD105 positivity (>90\%); high STRO-1 expression $(46 \%$ to $55 \%$ ); and negative for CD34. A similar colony-forming capacity was observed $(65 \pm 8 \%$ versus $73 \pm 5 \%$, MC-hfMSCs versus MNL-hfMSCs, $n=3, p>0.05$; Table 2$)$. The potential

Table 2. Characteristics of Human Fetal Mesenchymal Stem Cells Harvested by Trypsin, Tryple, and Collagenase from Cytodex 3 Microcarrier Surface $(n=3)$

\begin{tabular}{|c|c|c|c|c|c|}
\hline & \multicolumn{2}{|r|}{ Controls $^{\mathrm{a}}$} & \multicolumn{3}{|c|}{$\begin{array}{l}\text { Mode of cell harvesting from } \\
\text { Cytodex } 3 \text { microcarriers }\end{array}$} \\
\hline & MNL-hfMSC & MC-hfMSC-unharvested & Trypsin & TrypLE ${ }^{T M}$ express & Type I collagenase \\
\hline Treatment & Trypsin $5 \mathrm{~min}$ & NR & Trypsin $5 \mathrm{~min}$ & TrypLE 5 min & $\begin{array}{l}\text { Collagenase } \\
15 \mathrm{~min}\end{array}$ \\
\hline Harvesting efficiency (\%) & $>95$ & NR & $84 \pm 3$ & $61 \pm 3$ & $97 \pm 4$ \\
\hline Cell viability $(\%)$ & $>95$ & NR & $>95$ & $>95$ & $>95$ \\
\hline Immunophenotype (\%) & & NR & & & \\
\hline CD 73 & $96 \pm 4$ & & $95 \pm 4$ & $95 \pm 3$ & $96 \pm 3$ \\
\hline CD 90 & $97 \pm 3$ & & $98 \pm 2$ & $96 \pm 2$ & $97 \pm 4$ \\
\hline CD105 & $95 \pm 5$ & & $92 \pm 4$ & $93 \pm 6$ & $85 \pm 8$ \\
\hline STRO-1 & $46 \pm 8$ & & $55 \pm 6$ & $55 \pm 10$ & $47 \pm 9$ \\
\hline CD34 (negative marker) & $2.5 \pm 0.5$ & & $2.0 \pm 0.8$ & $0.8 \pm 0.4$ & $0.5 \pm 0.3$ \\
\hline Colony forming $(\%)$ & $73 \pm 5$ & NR & $65 \pm 8$ & $62 \pm 7$ & $61 \pm 7$ \\
\hline Doubling time $^{\mathrm{B}}(\mathrm{h})$ & $36 \pm 4$ & ND & $41 \pm 5$ & $40 \pm 1$ & $40 \pm 2$ \\
\hline ALP concentration ${ }^{c}$ (ng $/ 10^{6}$ cells) & $12.6 \pm 0.4$ & $0.27 \pm 0.07$ & $0.28 \pm 0.04$ & $0.19 \pm 0.02$ & $0.20 \pm 0.03$ \\
\hline Calcium deposition $^{\mathrm{d}}\left(\mu \mathrm{g} / 10^{6}\right.$ cells $)$ & $56 \pm 5$ & $71 \pm 4$ & $35 \pm 6$ & $27 \pm 4$ & $26 \pm 2$ \\
\hline
\end{tabular}

${ }^{a}$ Controls: MNL-hfMSC and MC-hfMSC-unharvested.

${ }^{\mathrm{b}}$ Doubling times were calculated based on results from three passages in monolayer cultures.

${ }^{c}$ ALP concentrations were measured before differentiation.

${ }^{\mathrm{d}}$ Calcium depositions were measured on Day 21 of differentiation.

$\mathrm{ND}$, not done; NR, not required. 
of scaling up of the Cytodex $3 \mathrm{MC}$ culture was demonstrated by increasing the culture volume from a $100-\mathrm{mL}$ spinner flask to a controlled 1-L bioreactor, achieving similar yields as with the smaller volume cultures. Even suspension of the MCs was achieved by using a pitched type impeller (Sartorius Biostat B-DCU) and agitation at $50 \mathrm{rpm}$. Oxygen levels were maintained above $30 \%$ air saturation by overhead aeration and pH was maintained between 7.2 and 7.3. Cell yields were similar to those obtained in a parallel spinner flask culture (as control): $6.0 \times 10^{5} \pm 0.2 \times 10^{5}$ cells $/ \mathrm{mL}$ (12-fold expansion) at day 8 and doubling time of $44 \mathrm{~h}$ (Fig. 3A). Cells harvested from the bioreactor retained MSC immunophenoype (Fig. 3B) and colony-forming ability $(64 \pm 10 \%)$ at similar levels to those obtained in MNL and spinner flask MC cultures. Glucose and L-glutamine daily consumption rates were 5.5 and $4.83 \mu \mathrm{mol} / 10^{6}$ cells, respectively, as compared with 12.5 and $4.69 \mu \mathrm{mol} / 10^{6}$ cells for MNL cultures showing increase in glucose metabolism in the aerated spinner flask cultures. Production rate of lactate and ammonium were 10 and $5.89 \mu \mathrm{mol} / 10^{6}$ cells per day, respectively, while MNL culture production rates were 30.5 and $5.58 \mu \mathrm{mol} / 10^{6}$ cells per day. Due to the high glycolytic activity of the hfMSCs $\left(\mathrm{Y}_{\text {Lac/Glc }}\right.$ of 1.81), at the later stages of cell growth, lactate concentration reached between 18 and $25 \mathrm{mM}$. These lactate levels are close to the MSC growth inhibitory levels $(28 \mathrm{mM})$ reported previ- ously, ${ }^{12,16,17}$ thus it is clear that in future development of MSC cultures, glucose feeding should be programmed to lower lactate production in culture. ${ }^{26}$ L-glutamine was found to be in excess in the culture media, and the ammonium concentration in the media reached levels between 1.9 and $2.2 \mathrm{mM}$, which are below the inhibitory level of $2.4 \mathrm{mM}$ reported for human MSC growth. ${ }^{12,17,26}$

\section{Establishment of an efficient MC culture cell harvesting method}

Next, we compared the kinetics of cell detachment from Cytodex 3 MC surface using three different enzymes: two nonspecific tryptic enzymes commonly used for cell dissociation (trypsin, TrypLE ${ }^{\mathrm{TM}}$ Express) and Type I Collagenase, which can specifically degrade the type 1 collagen coating on the Cytodex 3 MCs. We found that the use of TrypLE Express resulted in low cell harvesting efficiency of $61.0 \pm 2.8 \%$, which did not improve with increasing incubation time (Fig. 4). The use of Type I Collagenase resulted in a slow rate of cell detachment, with $73 \pm 3 \%$ of cell harvested at $5 \mathrm{~min}$, which rose to $97 \pm 4 \%$ at $15 \mathrm{~min}$. While in the case of trypsin, harvesting efficiency of $84 \pm 3 \%$ was achieved in just $5 \mathrm{~min}$ of incubation. In all cases, cell viability was more than $95 \%$.
FIG. 3. Scale up of hfMSC expansion in a 1-L controlled bioreactor. (A) Growth kinetics: $(\times)$ 1-L controlled bioreactor, $(\Delta)$ 100-mL spinner (control). (B) Immunophenotype of hfMSCs harvested from the bioreactor culture. A similar rate of growth and final cell density was seen for spinner flask and bioreactor culture $(n=3, p>0.05)$.

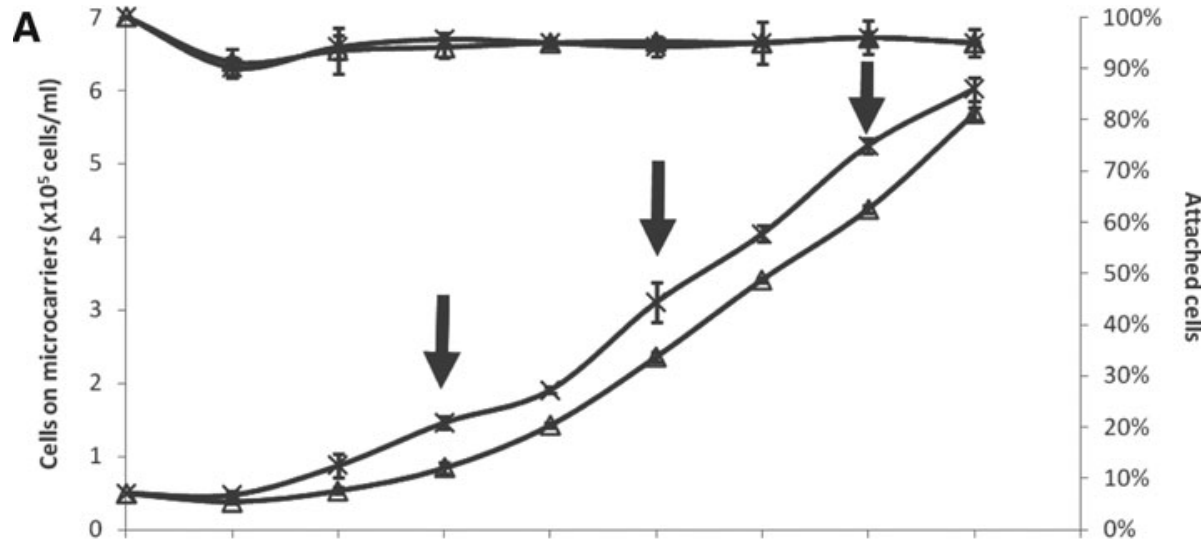

B
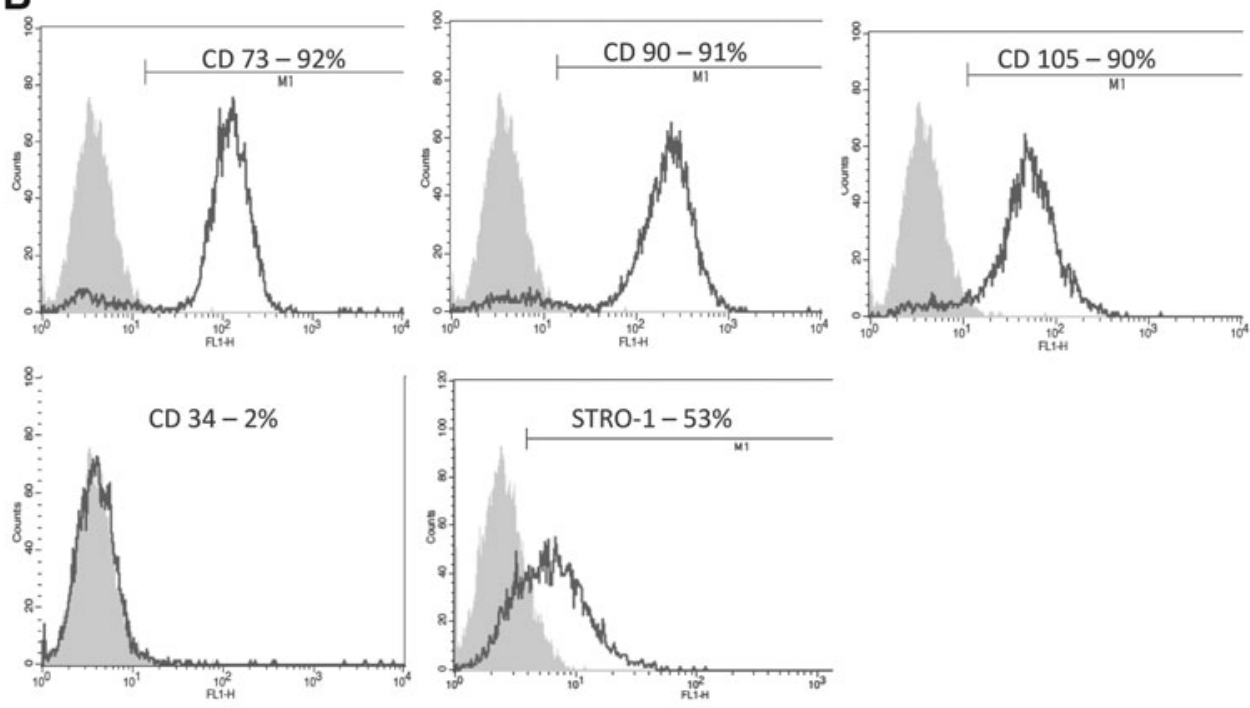


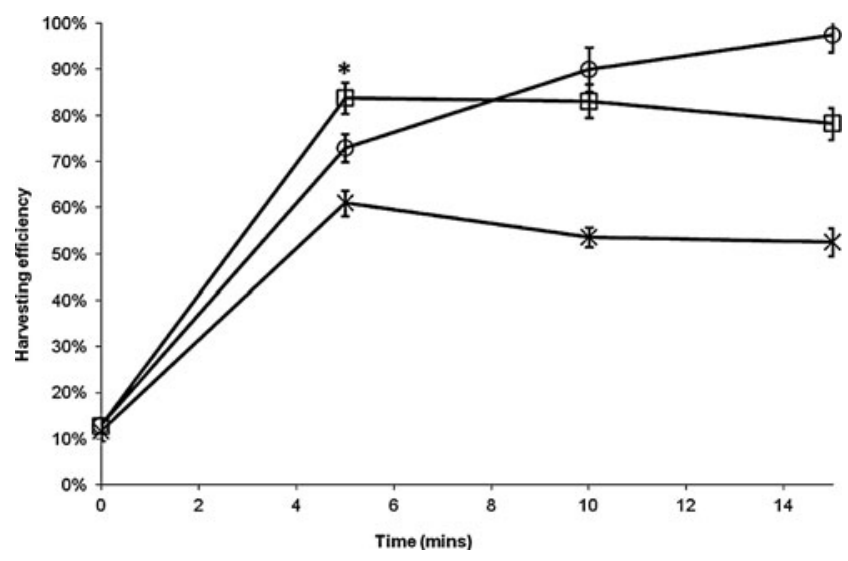

FIG. 4. Kinetics of hfMSC detachment from Cytodex 3 microcarrier surface by enzymatic treatment: ( $\square)$ Trypsin, $(\bigcirc)$ Type I Collagenase, and $(\times)$ TrypLETM Express. Statistical analysis shows that at 5 min of enzymatic treatment, trypsin had a significantly higher percentage of harvested cells than Type I Collagenase and TrypLETM Express $\left({ }^{*} p<0.01\right)$.

hfMSCs harvested from Cytodex 3 MCs (refer as MChfMSCs hereafter) by 5 min treatment with trypsin or TrypLE or $15 \mathrm{~min}$ with collagenase, were further characterized for their immunophenotype, colony-forming capacity, growth rate, and osteogenic differentiation potential. As control, hfMSCs harvested from MNL cultures (MNL-hfMSCs) by 5-min trypsin treatment were used (Table 2). We found similar immunophenotypes (95\%-96\% CD73, 96\%-98\% CD90, 85\%-95\% CD105, 46\%-55\% STRO-1, and 0\%-3\% for CD34 negative marker), colony-forming efficiency $(61 \pm 7 \%$ to $73 \pm 5 \%, n=5, p>0.05$ ), growth rates (doubling times of 36 to $41 \mathrm{~h}, n=3, p>0.05)$ and cell viability ( $>95 \%$ ) were obtained in all three enzyme treatment regimes of MC-hfMSCs or trypsin treatment of MNL-hfMSCs.

During differentiation, Cytodex 3 expanded, nonharvested hfMSCs plated on 2D cultures (MC-hfMSC-unharvested) achieved the highest level of calcium deposition of $71 \pm 4 \mu \mathrm{g} / 10^{6}$ cells as compared to $26-56 \mu \mathrm{g} / 10^{6}$ cells of MNL-hfMSCs and all three enzyme treatment regimes of MC-hfMSCs $(p<0.01)$. This difference indicates that the enzymatic cell harvesting methods degrades extracellular matrix (ECM) proteins and destroys cytoskeletal structure, and cell-cell interactions have an adverse effect on osteogenesis efficiency. ${ }^{23,33,34}$

High levels of calcium deposition were obtained by MNLhfMSC cultures as compared with three enzyme treatment regimes of MC-hfMSCs (56 vs. $26-35 \mu \mathrm{g} / 10^{6}$ cells, $n=3, p<0.05$; Table 2). This difference could stem from precommitment of the MNL harvested cells to 2D differentiation indicated by a higher initial ALP level as compared with MC-hfMSC cultures $\left(12.6 \pm 0.4\right.$ vs. $0.19-0.28 \mathrm{ng} / 10^{6}$ cells, $n=3, p<0.05$; Table 2). ${ }^{18-21,35-38}$

Comparison of the different enzyme treatments shows that trypsin generated single cell suspensions having higher osteogenic potential than TrypLE Express and Type I Collagenase (35 vs. $26-27 \mu \mathrm{g} / 10^{6}$ cells, $p<0.05$ ). Thus, the trypsin-based harvesting method was chosen as the method of choice for harvesting hfMSCs from the MC surface.

\section{D MNL cultures osteogenesis kinetics: comparison of MNL-hfMSC, MC-hfMSC, and MC-hfMSC-unharvested cultures}

To quantitatively compare the osteogenic differentiation potential of hfMSCs expanded on Cytodex $3 \mathrm{MC}$ and MNL, MNL-hfMSCs and MC-hfMSCs were plated in standard osteogenic differentiation conditions in MNL cultures. Additionally, we plated a similar number of MC-hfMSC-unharvested cells to interrogate the effect of trypsinization. Cell growth, calcium deposition, and ALP content were monitored for 21 days. During the differentiation process, MNL-hfMSC, MChfMSC, and MC-hfMSC-unharvested cultures grew in a similar manner showing 4.35- to 5.1-fold expansion in 21 days (Fig. 5A). Cell densities reached $9.1 \times 10^{4}-10.6 \times 10^{4}$ cells/ $\mathrm{cm}^{2}$ at day 21 of differentiation. This result indicates that the mode of cell expansion and the harvesting step did not affect cell growth properties. However, the ALP expression profile during differentiation was noticeably different for cells obtained from MNL-hfMSCs or MC-hfMSCs (Fig. 5B). As already mentioned, the basal level of ALP in MNLhfMSC culture was high $\left(12.6 \pm 0.4 \mathrm{ng} / 10^{6}\right.$ cells), and it continued to be up-regulated in the early osteogenic differentiation period achieving 2.2-fold increment to a maximum level of $27.4 \pm 2.9 \mathrm{ng} / 10^{6}$ cells at day 7 (Fig. 5B). In the later stage of differentiation, it decreased gradually to $3.35 \pm 0.09 \mathrm{ng} / 10^{6}$ cells at day 21 . This trend coincided with the ALP gene expression found in our previous study and other publications. ${ }^{8,35,38-40}$ MC-hfMSCs and MC-hfMSCs-unharvested had totally different ALP expression profiles during their 2D MNL differentiation process (Fig. 5B). These cells had a low basal level of ALP (MC-hfMSCs-unharvested: $0.24 \mathrm{ng} /$ $10^{6}$ cells, MC-hfMSCs: $0.28 \mathrm{ng} / 10^{6}$ cells), which increased gradually over the culture period of 21 days, achieving 16.3- and 10.6-fold increment for MC-hfMSCs-unharvested and MC-hfMSCs, respectively (Fig. 5B). Thus, it is clear that the mode of cell expansion (MNL vs. MC) affects the levels and pattern of ALP expression during osteogenesis, and further studies are needed in order to identify factors that lead to this phenomenon.

Kinetics of calcium deposition of hfMSCs did not correlate with the level of ALP expression. MC-hfMSCs-unharvested generated the bulk of their calcium deposition within the first 7 days of differentiation $\left(35 \pm 5 \mu \mathrm{g} / 10^{6}\right.$ cells) despite the presence of low levels of ALP $\left(1.73 \pm 0.53 \mathrm{ng} / 10^{6}\right.$ cells; Fig. $5 C)$. Thereafter, a gradual increase of calcium deposition was observed, achieving high levels of $53 \pm 8 \mu \mathrm{g}$ calcium/ $10^{6}$ cells by day 14 . This early generation of calcium deposit indicates that maintaining an intact ECM structure, nondisrupted cytoskeleton structure, and cell-cell interactions are important for initiation of an early osteogenic process as previously reported. ${ }^{29,40,41}$

Comparatively, both MNL-hfMSC and MC-hfMSC cultures deposited only small amounts of calcium during the first 7 days of differentiation (11.14-12.33 $\mu \mathrm{g} / 10^{6}$ cells; Fig. 5C). After this lag period, a gradual increase in calcium deposition was observed on day 14 of differentiation, with $21.8 \pm 3.0$ and $32 \pm 3.3 \mu \mathrm{g}$ calcium $/ 10^{6}$ cells obtained for MC-hfMSC and MNL-hfMSC cultures, respectively $(n=3$, $p<0.05)$. The major difference in calcium deposition between MNL-hfMSC and MC-hfMSC cultures was seen in late stages of differentiation, from days 14 to 21 , during which calcium 


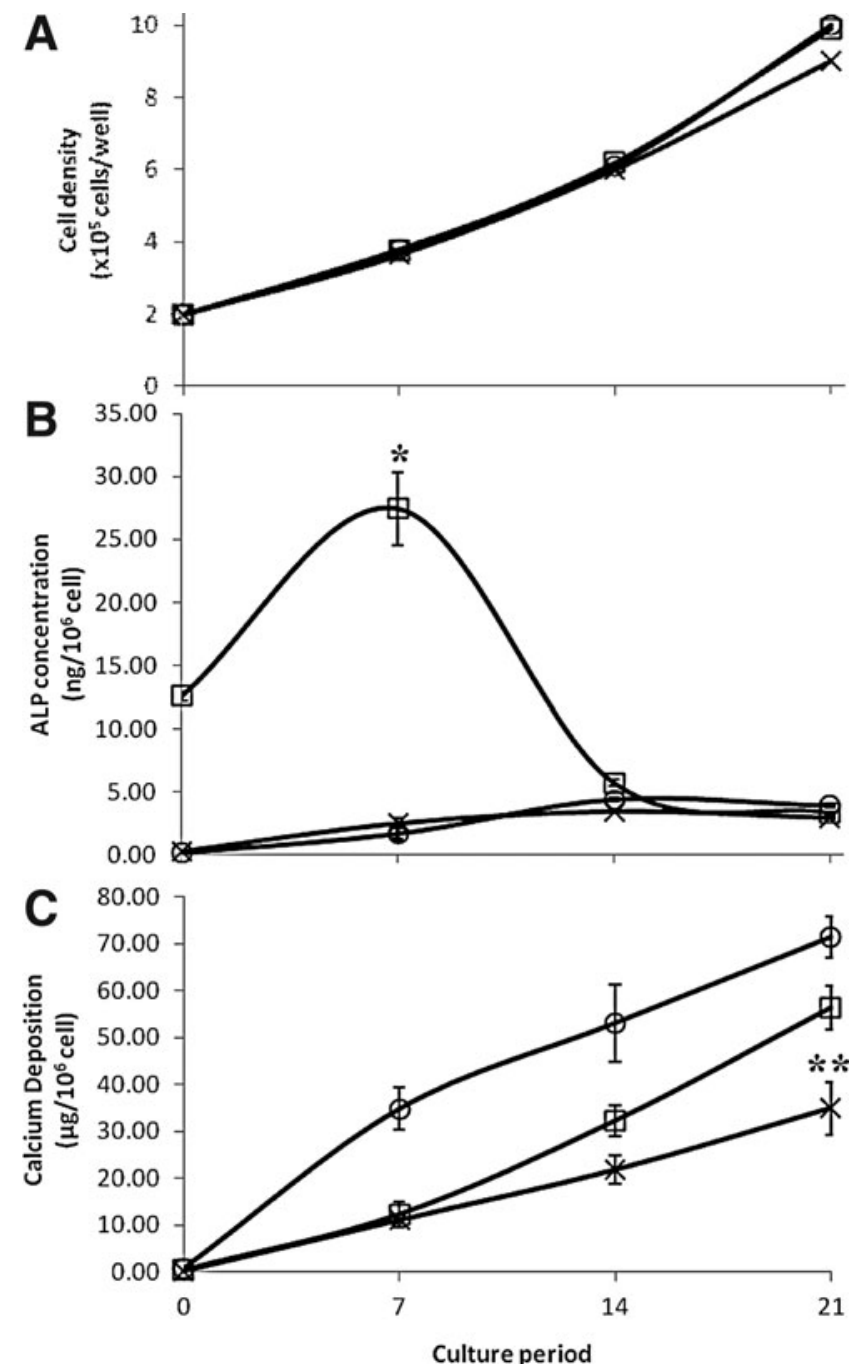

FIG. 5. Comparison of hfMSC growth, alkaline phosphatase (ALP) expression, and calcium deposition during two-dimensional (2D) in vitro osteogenesis. ( $\square$ ) Monolayer expanded hfMSCs (MNL-hfMSCs), $(\times)$ Microcarrier expanded hfMSCs (MC-hfMSCs), and (O) MC-hfMSCs that were not harvested from their microcarriers and were plated directly for osteogenic differentiation (MC-hfMSCs-unharvested). (A) Similar final cell densities were achieved for all three groups after 21 days of culture $(p>0.05)$. (B) MNLhfMSCs had a higher basal level of ALP, which peaked at day 7 of osteogenic differentiation than both MC-hfMSCs and MC-hfMSCs-unharvested $\left({ }^{*} p<0.01\right)$. ALP level of MChfMSCs and MC-hfMSCs-unharvested at day 7 do not differ significantly $(p>0.05)$. (C) Calcium deposition after 21 days of culture shows that MC-hfMSCs had significantly lower calcium depositions than MC-hfMSCs-unharvested and MNLhfMSCs $(* * p<0.05)$.

deposition increased to 56.2 and $35.0 \mu \mathrm{g}$ calcium $/ 10^{6}$ cells, respectively. The MC-hfMSC-unharvested culture produced the highest amount of calcium deposition of $71 \pm 4 \mu \mathrm{g}$ calcium/ $10^{6}$ cells after 21 days of osteogenic differentiation.

Therefore, the kinetics and quantity of calcium depositions in MNL 2D osteogenesis culture is affected by the method of cell expansion (MNL or MC culture) and whether disruption of the ECM through cell dissociation has been performed (harvested vs. nonharvested cells). We observed that cells expanded in 2D MNL static culture achieved higher levels of calcium deposition in 2D MNL differentiating cultures, but cells unharvested from MCs generated the highest levels of calcium.

\section{Osteogenesis kinetics in 3D scaffold cultures: comparison of hfMSCs harvested from MNL and MC cultures}

Next, we investigated the osteogenic potential of MChfMSCs and MNL-hfMSCs seeded within 3D macroporous scaffolds, which better approximated cellular behavior in native tissue and was a better representative for the generation of tissue engineered bone grafts.

We observed a similar cellular expansion of both MNLhfMSCs and MC-hfMSCs within the scaffold, which peaked at day 14 of differentiation in static culture conditions, achieving approximately 2.2-fold increment ( $n=4, p<0.05$; Fig. 6A). There was a slight fall in total dsDNA content by day 28 (Fig. 6), which may have reflected lack of viability beyond 2 weeks of static culture in these conditions as previously described. ${ }^{42}$ In contrast to what was observed in MNL 2D osteogenic differentiation platform (Fig. 5C), in the 3D scaffold culture, MChfMSCs underwent a higher degree of osteogenic differentiation, depositing 63.5\% more calcium than MNL-hfMSCs after 28 days $(n=4, p<0.05)$.
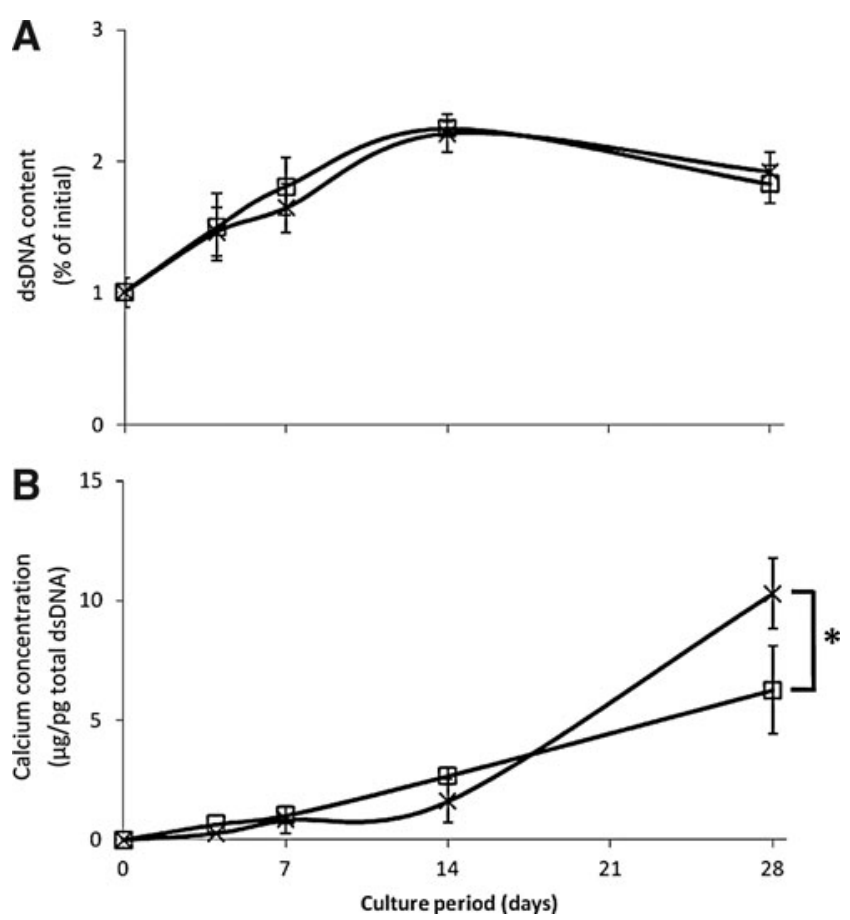

FIG. 6. Comparison of hfMSC growth and calcium deposition during three-dimensional (3D) in vitro osteogenesis of poly- $\varepsilon$-caprolactone-tri-calcium-phosphate (PCL-TCP) scaffold. The differentiating culture is seeded with MNL-hfMSCs $(\square)$ and MC-hfMSCs (×). (A) Both MC-hfMSCs and MLhfMSCs demonstrated a similar degree of expansion in 3D scaffolds over 28 days. (B) MC-hfMSCs laid down $63.5 \%$ more calcium over 28 days of osteogenic differentiation in 3D scaffolds $\left(n=4,{ }^{*} p<0.05\right)$. 
In vivo ectopic bone formation efficiency: comparison of hfMSCs harvested from MNL and MC cultures

Finally, we subcutaneously transplanted MC-hfMSCs and MNL-hfMSCs loaded into fibrin/HA pellets into immunodeficient mice to interrogate their in vivo ectopic bone formation capacity. Similar to our findings in the 3D scaffold-directed osteogenic differentiation paradigm, MC-HA implants resulted in formation of higher ectopic bone volume than MNL-HA, as seen by the micro-CT images, while in the control acellular implants (HA implant) only small pellets were observed (Fig. 7A). Quantitative micro-CT analysis showed acellular implants had a final volume of $5.0 \pm 2.2 \mathrm{~mm}^{3}$, while MNL-HA and MC-HA implants had final volumes of $12.5 \pm 2.2$ and $18.4 \pm 2.7 \mathrm{~mm}^{3}$, respectively $(47.2 \%$ higher amount of ectopic bone volume in MC-HA implants compared with MNL-HA implants, $n=5, p<0.05$; Fig. 7B). Using the volume of the acellular implants as a baseline refer- ence, the volumes of newly formed bone in MNL-HA and MC-HA were $7.5 \pm 3.1$ and $13.4 \pm 3.5 \mathrm{~mm}^{3}$, respectively (Table 3). Histological evaluation of the implants correlated positively with the results of micro-CT (Fig. 7C). Hematoxylin and eosin and von Kossa staining showed that MC-HA tissue implants were very compact, with more cells, and had darker calcium deposits than MNL-HA. MC-HA implants also contained more mature bone tissues than MNL-HA as seen by the darker blue stains of collagen I (Masson trichrome) and black calcified bone tissue by von Kossa staining.

\section{Discussion}

In this work, we demonstrated efficient cellular expansion of hfMSCs in Cytodex 3 MC stirred cultures in simple noncontrolled 100-mL spinner flasks. A 10-fold scale-up to a 1L controlled bioreactor was also successfully demonstrated. The difference between the MNL and MC methods of cell
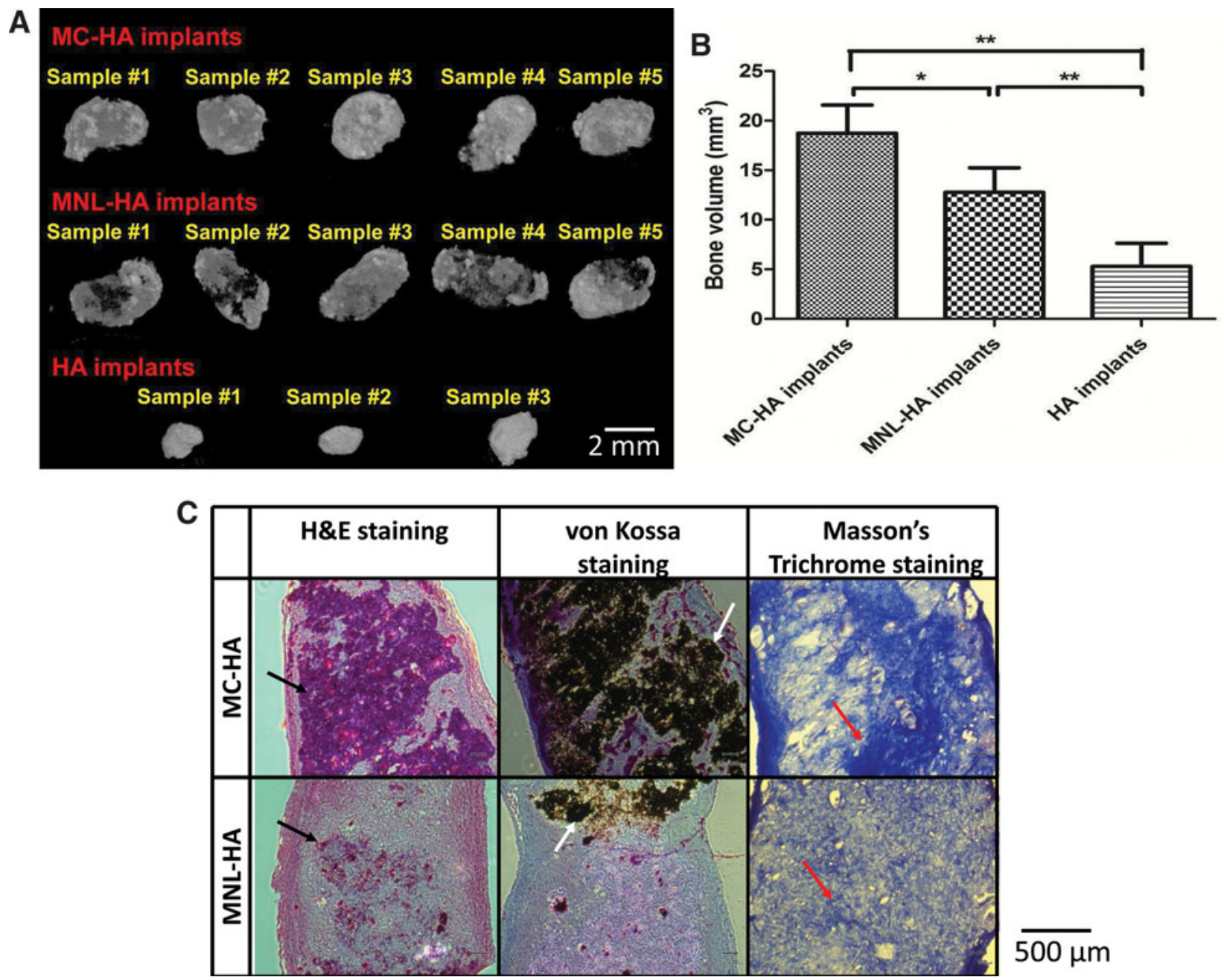

FIG. 7. Comparison of ectopic bone formation at 3 months. (A) Micro-computed tomography (micro-CT) 3D images of harvested implants showed a higher degree of mineralization in MC-hydroxyapatite (HA) implants than MNL-HA implants and acellular control, HA implants. (B) MC-HA implants achieved 47.2\% more ecoptic bone formation than MNL-HA implants $\left(n=5,{ }^{*} p<0.05,{ }^{* *} p<0.01\right)$. (C) Histological analysis of MNL-HA and MC-HA implants. More ectopic bone tissue with higher degree of mineralization was found with the MC-HA implants as compared to MNL-HA as confirmed by the hematoxylin and eosin (H\&E) staining, von Kossa staining, and Masson's trichrome staining. Black arrows indicate positive H\&E staining that confirms the presence of cells in ectopic bone samples. White arrows denote positive von Kossa staining, which shows the area of calcium deposition. Red arrows point to positive Masson's trichrome staining, revealing the presence of collagen I and indicating mature bone tissue. 
Table 3. Effect of Human Fetal Mesenchymal Stem Cell Mode of Expansion on Osteogenesis Efficiency in Three Differentiation Platforms

\begin{tabular}{|c|c|c|}
\hline \multirow[b]{2}{*}{$\begin{array}{l}\text { Differentiation/expansion } \\
\text { platform }\end{array}$} & \multicolumn{2}{|c|}{ Calcium deposition } \\
\hline & $\begin{array}{l}\text { Amount or } \\
\text { bone volume }\end{array}$ & $\begin{array}{c}\text { Fold } \\
\text { increase (\%) }\end{array}$ \\
\hline \multicolumn{3}{|l|}{ In vitro 2D (monolayer) } \\
\hline Monolayer & $56 \pm 5 \mu \mathrm{g} / 10^{6}$ cells & 37.5 \\
\hline Microcarrier & $35 \pm 6 \mu \mathrm{g} / 10^{6}$ cells & - \\
\hline \multicolumn{3}{|l|}{ In vitro $3 \mathrm{D}$ (scaffold) } \\
\hline Monolayer & $\begin{array}{l}6.3 \pm 1.8 \mu \mathrm{g} / \mathrm{pg} \\
\text { total dsDNA }\end{array}$ & - \\
\hline Microcarrier & $\begin{array}{l}10.3 \pm 1.5 \mu \mathrm{g} / \mathrm{pg} \\
\text { total dsDNA }\end{array}$ & 63.5 \\
\hline \multicolumn{3}{|l|}{$\begin{array}{l}\text { In vivo } 3 \mathrm{D} \text { (ectopic } \\
\text { bone), absolute } \\
\text { volume }\end{array}$} \\
\hline Monolayer & $12.5 \pm 2.2 \mathrm{~mm}^{3}$ & - \\
\hline Microcarrier & $18.4 \pm 2.7 \mathrm{~mm}^{3}$ & 47.2 \\
\hline \multicolumn{3}{|l|}{$\begin{array}{l}\text { In vivo 3D ectopic bone) } \\
\text { with acellular } \\
\text { implants as baseline }\end{array}$} \\
\hline Monolayer & $7.5 \pm 3.1 \mathrm{~mm}^{3}$ & - \\
\hline Microcarrier & $13.4 \pm 3.5 \mathrm{~mm}^{3}$ & 78.7 \\
\hline
\end{tabular}

expansion (agitated vs. static and collagen-coated dextran vs. tissue culture-treated polystyrene surface) did not affect the immunophenotype, colony-forming capacity, or proliferation rate of harvested hfMSCs (Table 2). However, cells harvested from MNL or MC cultures showed differential ALP expression and calcium deposition kinetics during osteogenic differentiation (Fig. 5). Comparatively, MNL-hfMSCs had a higher basal ALP level, which peaked at day 7 during osteogenic differentiation, with higher calcium deposition than MChfMSCs when assayed in traditional 2D MNL differentiation cultures post expansion. However, in 3D-based differentiation paradigms, MC-hfMSCs resulted in significantly more robust osteogenic differentiation both in vitro and in vivo, suggesting its utility for BTE.

MSCs are one of the most promising cell sources for BTE applications. However, one of the key challenges in clinical translation has been the need for $10^{8}$ to $10^{9}$ cells required. ${ }^{43}$ Thus, we first performed a head-to-head comparison of different MCs to define the appropriate MC for expansion of hfMSCs for BTE applications, characterized their immunophenotype and osteogenic potential in a series of 2D and 3D assays, and finally probed into their in vivo ectopic bone-forming capacity. We showed that the collagen I-coated cross-linked dextran Cytodex 3 MCs support efficient propagation of hfMSCs, with a high rate of cell attachment ( $>90 \%$ at $24 \mathrm{~h}$ ) and spreading, high levels of cell expansion and final yield, and low level of cell-MC aggregation, and afford efficient cell harvesting.

We obtained an average maximal cell yield of $8.3 \times$ $10^{4} \pm 0.9 \times 10^{5}$ cells $/ \mathrm{mL}$ using Cytodex $3 \mathrm{MCs}$, which is at the higher end of the yields reported in literature. Cell expansion fold of 7 to 18 fold with final cell yield of $2.0 \times 10^{5}$ to $5.5 \times 10^{5}$ cells $/ \mathrm{mL}^{18,19,44}$ has been reported for the porous MC Cultispher, and fold expansion of 11 to 27 with final cell yield of $1.1 \times 10^{5}$ to $6 \times 10^{5}$ cells $/ \mathrm{mL}$ was reported for human MSCs propagated on nonporous Cytodex MCs. ${ }^{16,32}$
Enzyme-based cell harvesting methods from MNL culture are well established. However, harvesting of cells from the MC surface is more challenging due to the beaded nature, limited accessibility of the enzyme to the cells on the MCs, and the need to separate cells from the MCs. ${ }^{45}$ An effective way of trypsin-based dissociation followed by $70-\mu \mathrm{m}$ mesh sieving protocol was applied, in which high harvesting efficiencies of $>80 \%$ were achieved and more importantly, the harvested cells exhibit higher levels of calcium deposition during differentiation as compared with the cells harvested by TrypLE or collagenase treatment.

We observed a delay in calcium deposition in both 2D and 3D differentiation cultures seeded with trypsin-harvested MNL-hfMSCs or MC-hfMSCs but not with MC-hfMSCsunharvested. This delay can be attributed to the proteolytic cleavage of ECM proteins from the cell surface, destruction of cytoskeleton structure, and breakage of cell-cell interactions during cell detachment from the growth substrate. ${ }^{23,29,33,34,41}$ The lag period is needed for generation of ECM proteins, reorganization of cytoskeleton, and generation of cell-cell contacts, which leads to later stages of preosteoblast, osteoblast, and eventually into osteocytes differentiation. ${ }^{37,40}$ It has been demonstrated previously that ECM deposited by cells, may play a critical role in regulating cellular functionality and maintaining the survival of cells in vitro and in vivo, through intracellular signaling triggers and the interactions between adhesion molecules and ECM. ${ }^{33}$ Disruption of MSC cytoskeleton by cytochalasin $\mathrm{D}$ treatment resulted in a delay of at least 8 days in recovery of osteogenesis markers and leads to lower levels of calcium deposition. ${ }^{40}$ Thus, the development of implantable MCs could be advantageous for BTE and may also result in reduced apoptosis compared with trypsinized MNL MSCs as shown by Yang et al. ${ }^{22}$ with rat MSCs.

MNL-hfMSC cultures have a high basal ALP expression $\left(12.6 \pm 0.4 \mathrm{ng} / 10^{6}\right.$ cells) peaking at 2.2 fold at day 7 of culture, which is typical of MSC differentiation as described by us and others. ${ }^{8,35,38-40}$ Comparatively, both MC-hfMSC and MChfMSC-unharvested cultures showed far lower basal expression of ALP (45-52 fold lower), and a gradual increase of ALP expression over the culture period, reaching a level of 2.968$3.92 \mathrm{ng} / 10^{6}$ cells on day 21 (10.6- to 16.3 -fold increase). In contrast, calcium deposition demonstrates a different pattern, MC-hfMSCs cultured in a 3D environment within osteo-inductive macroporous scaffolds, or when implanted as a HA-pellet in mice, achieved $64 \%$ more calcium deposition and $47 \%$ more bone volume than MNL-hfMSCs $(p<0.05)$.

To date, the "gold standard" to determine the osteogenic potency of MSCs is to carry out in vivo ectopic bone formation assays, in which MSCs are mixed with HA and implanted into subcutaneous sites in mice. ${ }^{46}$ This is because in vivo osteogenesis of MSCs remains a complex process and is still poorly defined. In vitro functional assays and the traditional osteogenic molecular markers such as ALP activity, calcium deposition, or qRT-PCR of osteoblastic markers such as ALP, collagen type 1, Runx2, osteopontin, and bone sialoprotein have been found to have no significant correlation to in vivo bone-forming potency of MSCs. ${ }^{37,47}$ Qualitatively, we observed that there are more cells present in MC-hfMSC implants versus MNL-hfMSC implants (Fig. 7C). This observation might be attributed to reduction in apoptosis or higher proliferation of MC-hfMSCs versus MNL-hfMSCs after fibrin encapsulation. Indeed, cell numbers or mass will increase the 
size of bone volume formed. However, we must be mindful that bone formation and regeneration is a dynamic process, which is constantly undergoing remodeling. Hence, rather than looking at a single aspect of osteogenesis such as cell survival or cell proliferation within the implant, which can fuel misleading conclusions, we chose to perform the end point study of bone volume generated and qualitative assessment of bone maturity by histology. The results of higher bone volume and maturity provide direct and important information on the potential of clinical applications such as treatment of nonunion fractures. Therefore, our head-to-head comparisons of MC- and MNL-expanded hfMSCs is the first to investigate calcium deposition on 3D scaffolds and in vivo ectopic bone formation over 3 months that is relevant to bone repair of nonunion defects.

While the exact mechanism underlying this discrepancy between 2D and 3D osteogenic potential is unknown at the moment, it is possible that it can be influenced by a few factors. Firstly, it is well recognized that the 3D environment allows for more efficient cell-cell communication and cell spreading, which mimics the in vivo situation much better than 2D MNL cultures. In fact, our findings are in keeping with many other reports that demonstrated that gene expression, signaling, and morphology of cells cultured in 2D are considerably different from those cultured in 3D and in vivo, with $3 \mathrm{D}$ cultures generally taken to imitate the $3 \mathrm{D}$ environment with more fidelity. ${ }^{48-52}$ Moreover, for cells that have achieved good spreading, there is an increase in RhoA and Rho kinase (ROCK) activity that can lead to osteogenesis rather than adipogenesis. ${ }^{29,53}$ It has also been shown in the context of chondrogenic cell types, which compared MC to MNL expansion, that MC expansion enhances the chondrogenic phenotype and redifferentiation of chrondrocytes. ${ }^{54-56}$ Secondly, we found premature activation of ALP seen in MNL-hfMSC culture compared to MC-hfMSC culture, suggesting that a possible reduction in the more primitive population of MSCs residing within the bulk culture. This in turn may manifest only in a more robust model of osteogenesis found in 3D cultures and within in vivo settings. Thirdly, a key difference between MC and MNL cultures is the need for MNL cultures to undergo repeated subcultures with trypsinization in order to achieve significant numbers. This not only increases the possibility of introduction of impurities and infectious agents, the removal of ECM may affect the functionality and survival status of cells, which depends on specific interactions of integrins and other key adhesion molecules. ${ }^{33}$ This in turn may lead to the gradual loss of multipotentiality and senescence of cells during the conventional tissue culture expansion process. ${ }^{57-64}$ With the large surface area available to cells on MCs, the repeated trypsinization process is limited to each time the bioreactor is harvested, and thus provides better preservation of ECM, which in turn may lead to better cellular survival and performance. This has been shown in a recent study on MC-based expansion of rat MSCs, which led to reduced cellular apoptosis of implanted cells and better bone regeneration. ${ }^{22}$ Finally, a dynamic culture system has been used in conjunction with MC cultures, which leads to better distribution of nutrients and removal of waste products that may limit and affect cellular expansion. ${ }^{12,13,17}$ Moreover, it was reported that induction of osteogenic differentiation through exposure to fluid flow shear stress activates RhoA and ROCKII, affecting actin fibril cytoskeleton tension. ${ }^{53}$
In conclusion, we have successfully demonstrated an MCbased scalable expansion technique to produce large quantities of hfMSCs. Beyond the large-scale expansion potential, the different mode of hfMSC propagation in stirred cultures on the surface of collagen-based MCs results in higher osteogenic efficiency in 3D in vitro scaffold systems and in vivo ectopic bone generation in mice (Table 3). These findings suggest that the hfMSC MC expansion platform can efficiently replace the traditional static MNL culture in BTE and regenerative medicine.

\section{Acknowledgments}

This work is funded generously by Agency for Science, Technology, and Research (A*STAR) Singapore and National Medical Research Council, Singapore (NMRC/1268/2010). J.K.Y.C. and M.C. received salary support from the National Medical Research Council, Singapore (NMRC/CSA/012/ 2009 and NMRC/CSA/009/2009).

\section{Author Disclosure Statement}

No competing financial interests exist.

\section{References}

1. O'Donoghue K, Chan J. Human fetal mesenchymal stem cells. Curr Stem Cell Res Ther. 2006;1:371-386.

2. Zhang ZY, Teoh SH, Hui JH, et al. The potential of human fetal mesenchymal stem cells for off-the-shelf bone tissue engineering application. Biomaterials. 2012;33:2656-2672.

3. Caplan AI, Correa D. The MSC: an injury drugstore. Cell Stem Cell. 2011;9:11-15.

4. Prockop DJ, Oh JY. Mesenchymal stem/stromal cells (MSCs): role as guardians of inflammation. Mol Ther. 2012;20:14-20.

5. Le Blanc K. Immunomodulatory effects of fetal and adult mesenchymal stem cells. Cytotherapy. 2003;5:485-489.

6. Le Blanc K, Ringdén O. Immunobiology of human mesenchymal stem cells and future use in hematopoietic stem cell transplantation. Biol Blood Marrow Transplant. 2005;11: 321-324.

7. Bruder SP, Jaiswal N, Ricalton NS, et al. Mesenchymal stem cells in osteobiology and applied bone regeneration. Clin Orthop Relat Res. 1998;355(Suppl):S247-256.

8. Zhang ZY, Teoh SH, Chong MS, et al. Superior osteogenic capacity for bone tissue engineering of fetal compared with perinatal and adult mesenchymal stem cells. Stem Cells. 2009;27:126-137.

9. Zhang ZY, Teoh SH, Chong MS, et al. Neo-vascularization and bone formation mediated by fetal mesenchymal stem cell tissue-engineered bone grafts in critical-size femoral defects. Biomaterials. 2010;31:608-620.

10. Mesoblast. West Australian - Stem Cells Used to Speed Fracture Repair. 2008. Available at www.mesoblast.com/ news_whattheysay13.php (accessed October 25, 2012).

11. Rowley J, Abraham E, Campbell A, et al. Meeting lot-size challenges of manufacturing adherent cells for therapy. BioProcess International. 2012;10:16-22.

12. Schop D, Janssen FW, Borgart E, et al. Expansion of mesenchymal stem cells using a microcarrier-based cultivation system: growth and metabolism. J Tissue Eng Regen Med. 2008;2:126-135.

13. Oh SK, Chen AK, Mok Y, et al. Long-term microcarrier suspension cultures of human embryonic stem cells. Stem Cell Res. 2009;2:219-230. 
14. Pharmacia Fine Chemicals Ab. Microcarrier Cell Culture: Principles \& Methods. Almqvist \& Wiksell Tryckeri: Uppsala Pharmacia, 1981.

15. Sart S, Schneider YJ, Agathos SN. Influence of culture parameters on ear mesenchymal stem cells expanded on microcarriers. J Biotechnol. 2010;150:149-160.

16. Eibes G, Dos Santos F, Andrade PZ, et al. Maximizing the ex vivo expansion of human mesenchymal stem cells using a microcarrier-based stirred culture system. J Biotechnol. 2010;146:194-197.

17. Schop D, Van Dijkhuizen-Radersma R, Borgart E, et al. Expansion of human mesenchymal stromal cells on microcarriers: growth and metabolism. J Tissue Eng Regen Med. 2010;4:131-140.

18. Santos FD, Andrade PZ, Abecasis MM, et al. Toward a clinical-grade expansion of mesenchymal stem cells from human sources: a microcarrier-based culture system under xeno-free conditions. Tissue Eng Part C Methods. 2011;17:1201-1210.

19. Sun LY, Hsieh DK, Syu WS, et al. Cell proliferation of human bone marrow mesenchymal stem cells on biodegradable microcarriers enhances in vitro differentiation potential. Cell Prolif. 2010;43:445-456.

20. Zhou Y, Yan Z, Zhang H, et al. Expansion and delivery of adipose-derived mesenchymal stem cells on three microcarriers for soft tissue regeneration. Tissue Eng Part A 2011;17:29812997.

21. Tseng PC, Young TH, Wang TM, et al. Spontaneous osteogenesis of MSCs cultured on 3D microcarriers through alteration of cytoskeletal tension. Biomaterials. 2012;33:556-564.

22. Yang Y, Hallgrimsson, Putnins EE. Craniofacial defect regeneration using engineered bone marrow mesenchymal stromal cells. J Biomed Mater Res A 2011;99:74-85.

23. Yang Y, Rossi FM, Putnins EE. Ex vivo expansion of rat bone marrow mesenchymal stromal cells on microcarrier beads in spin culture. Biomaterials. 2007;28:3110-3120.

24. Parliament of Great Britain, Polkinghorne J. Review of the Guidance on the Research Use of Fetuses and Fetal Material. London: HMSO, 1992.

25. Chan J, Kumar S, Fisk NM. First trimester embryo-fetoscopic and ultrasound-guided fetal blood sampling for ex vivo viral transduction of cultured human fetal mesenchymal stem cells. Hum Reprod. 2008;23:2427-2437.

26. Chen X, Chen A, Woo TL, et al. Investigations into the metabolism of two-dimensional colony and suspended microcarrier cultures of human embryonic stem cells in serum-free media. Stem Cells Dev. 2010;19:1781-1792.

27. Chen $\mathrm{AK}, \mathrm{Chen} \mathrm{X}, \mathrm{Choo} \mathrm{AB}$, et al. Critical microcarrier properties affecting the expansion of undifferentiated human embryonic stem cells. Stem Cell Res. 2011;7:97-111.

28. Pittenger MF, Mackay AM, Beck SC, et al. Multilineage potential of adult human mesenchymal stem cells. Science. 1999;284:143-147.

29. McBeath R, Pirone DM, Nelson CM, et al. Cell shape, cytoskeletal tension, and RhoA regulate stem cell lineage commitment. Dev Cell. 2004;6:483-495.

30. Hu WS, Meier J, Wang DI. A mechanistic analysis of the inoculum requirement for the cultivation of mammalian cells on microcarriers. 1985. Biotechnol Bioeng. 2006;95:306-316.

31. Shahar A, Reuveny S, David Y, et al. Cerebral neurons, skeletal myoblasts, and cardiac muscle cells cultured on macroporous beads. Biotechnol Bioeng. 1994;43:826-831.

32. Hewitt CJ, Lee K, Nienow AW., et al. Expansion of human mesenchymal stem cells on microcarriers. Biotechnol Lett. 2011;33:2325-2335.
33. Reddig PJ, Juliano RL. Clinging to life: cell to matrix adhesion and cell survival. Cancer Metastasis Rev. 2005;24:425-439.

34. Benoit DS, Tripodi MC, Blanchette JO, et al. Integrin-linked kinase production prevents anoikis in human mesenchymal stem cells. J Biomed Mater Res A. 2007;81:259-268.

35. Malaval L, Modrowski D, Gupta AK, et al. Cellular expression of bone-related proteins during in vitro osteogenesis in rat bone marrow stromal cell cultures. J Cell Physiol. 1994;158:555-572.

36. Goshima J, Goldberg VM, Caplan AI. The osteogenic potential of culture-expanded rat marrow mesenchymal cells assayed in vivo in calcium phosphate ceramic blocks. Clin Orthop Relat Res. 1991;262:298-311.

37. Larsen $\mathrm{KH}$, Frederiksen CM, Burns JS, et al. Identifying a molecular phenotype for bone marrow stromal cells with in vivo bone-forming capacity. J Bone Miner Res. 2010;25: 796-808.

38. Beck GR Jr, Sullivan EC, Moran E, et al. Relationship between alkaline phosphatase levels, osteopontin expression, and mineralization in differentiating MC3T3-E1 osteoblasts. J Cell Biochem. 1998;68:269-280.

39. Mathews S, Gupta PK, Bhonde R, et al. Chitosan enhances mineralization during osteoblast differentiation of human bone marrow-derived mesenchymal stem cells, by upregulating the associated genes. Cell Prolif. 2011;44:537-549.

40. Rodriguez JP, Gonzalez M, Rios S, et al. Cytoskeletal organization of human mesenchymal stem cells (MSC) changes during their osteogenic differentiation. J Cell Biochem. 2004;93:721-731.

41. Decaris ML, Mojadedi A, Bhat A, et al. Transferable cell-secreted extracellular matrices enhance osteogenic differentiation. Acta Biomater. 2012;8:744-752.

42. Zhang ZY, Teoh SH, Teo EY, et al. A comparison of bioreactors for culture of fetal mesenchymal stem cells for bone tissue engineering. Biomaterials. 2010;31:8684-8695.

43. Horwitz EM, Prockop DJ, Fitzpatrick LA, et al. Transplantability and therapeutic effects of bone marrow-derived mesenchymal cells in children with osteogenesis imperfecta. Nat Med. 1999;5:309-313.

44. Wu QF, Wu CT, Dong B, et al. [Cultivation of human mesenchymal stem cells on macroporous CultiSpher G microcarriers]. Zhongguo Shi Yan Xue Ye Xue Za Zhi. 2003;11:1521. (In Chinese.)

45. Yang HS, Jeon $\mathrm{O}$, Bhang $\mathrm{SH}$, et al. Suspension culture of mammalian cells using thermosensitive microcarrier that allows cell detachment without proteolytic enzyme treatment. Cell Transplant. 2010;19:1123-1132.

46. Arvidson K, Abdallah BM, Applegate LA, et al. Bone regeneration and stem cells. J Cell Mol Med. 2011;15:718-746.

47. Janicki $P$, Boeuf $S$, Steck E, et al. Prediction of in vivo bone forming potency of bone marrow-derived human mesenchymal stem cells. Eur Cell Mater. 2011;21:488-507.

48. Malda J, Frondoza CG. Microcarriers in the engineering of cartilage and bone. Trends Biotechnol. 2006;24:299-304.

49. Melero-Martin JM, Dowling MA, Smith M, et al. Expansion of chondroprogenitor cells on macroporous microcarriers as an alternative to conventional monolayer systems. Biomaterials. 2006;27:2970-2979.

50. Souza GR, Molina JR, Raphael RM, et al. Three-dimensional tissue culture based on magnetic cell levitation. Nat Nanotechnol. 2010;5:291-296.

51. Cukierman E, Pankov R, Stevens DR, et al. Taking cell-matrix adhesions to the third dimension. Science. 2001;294:17081712. 
52. Kale S, Biermann S, Edwards C, et al. Three-dimensional cellular development is essential for ex vivo formation of human bone. Nat Biotechnol. 2000;18:954-958.

53. Arnsdorf EJ, Tummala P, Kwon RY, et al. Mechanically induced osteogenic differentiation - the role of RhoA, ROCKII and cytoskeletal dynamics. J Cell Sci. 2009;122:546-553.

54. Malda J, Kreijveld E, Temenoff JS, et al. Expansion of human nasal chondrocytes on macroporous microcarriers enhances redifferentiation. Biomaterials. 2003;24:5153-5161.

55. Malda J, Van Blitterswijk CA, Grojec M, et al. Expansion of bovine chondrocytes on microcarriers enhances redifferentiation. Tissue Eng. 2003;9:939-948.

56. Frondoza C, Sohrabi A, Hungerford D. Human chondrocytes proliferate and produce matrix components in microcarrier suspension culture. Biomaterials. 1996;17:879-888.

57. Bruder SP, Jaiswal N, Haynesworth SE. Growth kinetics, selfrenewal, and the osteogenic potential of purified human mesenchymal stem cells during extensive subcultivation and following cryopreservation. J Cell Biochem. 1997;64: 278-294.

58. Javazon EH, Beggs KJ, Flake AW. Mesenchymal stem cells: paradoxes of passaging. Exp Hematol. 2004;32:414-425.

59. Meredith JE Jr, Fazeli B, Schwartz MA. The extracellular matrix as a cell survival factor. Mol Biol Cell. 1993;4:953-961.

60. Werb Z. ECM and cell surface proteolysis: regulating cellular ecology. Cell. 1997;91:439-442.

61. Ginsberg MH, Schwarzbauer JE. Cell-to-cell contact and extracellular matrix. Curr Opin Cell Biol. 2008;20:492-494.
62. Bornstein P. Cell-matrix interactions: the view from the outside. Methods Cell Biol. 2002;69:7-11.

63. Lobb RR. Cell-matrix adhesion research and the development of biotherapeutics. Methods Cell Biol. 2002;69:17-23.

64. Ekblom P, Timpl R. Cell-to-cell contact and extracellular matrix. A multifaceted approach emerging. Curr Opin Cell Biol. 1996;8:599-601.

Address correspondence to: Dr. Steve Oh

Bioprocessing Technology Institute A*STAR (Agency for Science, Technology and Research) 20 Biopolis Way, \#06-01 Centros Singapore 138668

Singapore

E-mail: steve_oh@bti.a-star.edu.sg

Dr. Jerry Chan Experimental Fetal Medicine Group Department of Obstetrics and Gynecology Yong Loo Lin School of Medicine National University of Singapore 5 Lower Kent Ridge Road Singapore 119074 Singapore

E-mail: jerrychan@nus.edu.sg 